\title{
Articulação entre primário e secundário na era Vargas: crítica do papel do estado*
}

\author{
Maria Angélica Pedra Minhoto \\ Universidade de São Paulo
}

\section{Resumo}

0 objetivo do texto é o de caracterizar o peso seletivo do exame de admissão ao ginásio, entre os anos de 1931 e 1945, tendo em vista a política educacional do governo de Getúlio Vargas voltada ao Ensino Secundário. Para tanto, verificou-se o padrão de recrutamento estabelecido pelo exame e as relações existentes entre a regulamentação jurídica e o comportamento dos estabelecimentos de ensino frente às normas. 0 levantamento de informações foi feito em arquivos de cinco instituições de ensino, localizadas na cidade de São Paulo, em funcionamento à época, e que permanecem abertas até hoje. Para a análise do percurso escolar dos alunos entre os Ensinos Primário e Secundário, foi utilizado o conceito de segmentação elaborado por Fritz Ringer em obra que descreve e compara as diferentes configurações de sistemas educacionais da Europa e dos Estados Unidos. Para o autor, o sistema educacional segmentado é aquele que oferece caminhos paralelos de estudos, separados por barreiras institucionais, pelo currículo e por diferenças de origem social dos estudantes. Os resultados obtidos indicam que o exame legitimou um padrão específico de recrutamento de alunos e camuflou a existência de barreiras institucionais no ensino elementar. Ademais, as estratégias desenvolvidas pelas instituições privadas para contornar sistematicamente a regulamentação jurídica do exame permitiram entrever limites a papel repressivo e interventor do Estado da época.

\section{Palavras-chave}

Exame de admissão ao ginásio - Política educacional - Era Vargas.

\author{
Correspondência: \\ Maria Angélica Pedra Minhoto \\ Faculdade de Educação - USP \\ Av. da Universidade, 308 - sala 206 \\ 05508-040 - São Paulo - SP \\ e-mail: angelicape@usp.br
}




\title{
Articulation between primary and secondary education in the Vargas period: critique of the role of the State*
}

\author{
Maria Angélica Pedra Minhoto \\ Universidade de São Paulo
}

\begin{abstract}
Contact:
Maria Angélica Pedra Minhoto Faculdade de Educação - USP

Av. da Universidade, 308 - sala 206

05508-040 - São Paulo - SP

e-mail: angelicape@usp.br
\end{abstract}

\begin{abstract}
The objective of this text is to characterize the relative weight of the admission exam to the gymnasium (the four series following primary education) in the years between 1931 and 1945, in view of the educational policy for Secondary Education during the govern of Getúlio Vargas. To this end, we have examined the pattern of recruiting established by the exam, and the relations existing between the juridical regulations and the ensuing behavior of institutes of education. Information were gathered from the archives of five institutes of education located in the city of São Paulo, which were functioning at that time and remain in operation today. The analysis of the school trajectory of the students between Primary and Secondary Education made use of the concept of segmentation as proposed by Fritz Ringer in a work that describes and compares the different configurations of education systems in Europe and the USA. To that author the segmented education system is one that offers parallel paths of study separated by institutional barriers, by curriculum, and by differences in social origin between students. The results obtained indicate that the exam legitimized a specific pattern of recruitment of pupils, and camouflaged the existence of institutional barriers in elementary education. Furthermore, the strategies developed by the private institutions to circumvent systematically the juridical regulations of the exam give us a glimpse of the repressive and intervening role of the State at that time.
\end{abstract}

\section{Keywords}

Entrance exam to the Gymnasium - Educational policy - Vargas period. 
0 texto tem como objetivo caracterizar o peso seletivo do exame de admissão ao ginásio, nas décadas de 1930 e 1940, tendo em vista a política pública do governo Vargas para o ensino secundário. Para tanto, verificou-se o padrão de recrutamento estabelecido pelo exame, bem como as relações entre os estímulos presentes nas determinações legais para a organização do exame e as respostas dos estabelecimentos de ensino a tais prescrições.

0 levantamento das informações foi realizado entre os anos de 2004 e 2006, em arquivos de cinco instituições de ensino secundário, localizadas na cidade de São Paulo e que permanecem em funcionamento até hoje, e limitou-se a uma amostra de três coortes (1935, 1939 e 1943). Os critérios para a seleção das instituições que compuseram a amostra foram: instituição pública (mista) [havia apenas uma que funcionava na cidade, no período em apreço] e quatro instituições privadas, sendo duas católicas - uma de público feminino e outra masculino -, uma protestante (mista) e uma laica (mista).

Todas as informações coligidas referemse a uma amostra de $20 \%$ do total de alunos aprovados em exames de admissão e matriculados na primeira série ginasial dos respectivos estabelecimentos. Além disso, realizou-se levantamento da documentação legal que incidiu sobre o exame no período. Serão discutidas neste trabalho algumas das principais prescrições legais.

Para a análise do percurso escolar dos estudantes entre o Primário e o Secundário, foi utilizado o conceito de segmentação elaborado por Ringer (1979) em obra que descreve e compara as diferentes configurações dos sistemas educacionais da Europa e dos Estados Unidos. Para o autor, o sistema educacional segmentado é aquele que oferece caminhos paralelos de estudos, separados por barreiras institucionais, pelo currículo e por diferenças de origem social dos estudantes.

Constatou-se o papel contraditório do Estado no que se refere à articulação entre os
Ensinos Primário e Secundário, à época, visto que, à medida que instituiu um exame com o objetivo explícito de regular a progressão escolar do aluno em termos de mérito, buscando qualificar o Ensino Secundário, acabou preservando, e mesmo fortalecendo, a dualidade presente na escola elementar. A análise se assentou na crítica imanente dos mecanismos reprodutores da desigualdade social, apesar de toda a argumentação "progressista" arregimentada naquele momento.

\section{Percurso escolar anterior ao exame de admissão ao ginásio}

0 exame de admissão ao ginásio foi instituído em 1931, pelo Decreto $n^{\circ} 19.890$, de 18/ 04/31', que reformou o Ensino Secundário, perdurando oficialmente até 1971. Para o ingresso no primeiro ano ginasial, estabeleceu as seguintes condições: o candidato deveria ter idade mínima de 11 anos; ser aprovado em exame e ter classificação suficiente, isto é, o número de vagas na instituição de ensino deveria bastar para que pudesse efetuar a matrícula; a inscrição só poderia se realizar mediante requerimento, atestado de vacinação antivariólica e recibo de pagamento de taxa de inscrição, além de ser limitada a um único estabelecimento de ensino (arts. 18 a 23, do Decreto $n^{\circ} 19.890$, de 18/04/31).

Ao longo dos 40 anos em que vigoraram os exames, foi possível observar inúmeras alterações legais na forma, no conteúdo e no funcionamento propostos inicialmente para a seleção dos secundristas. No entanto, nenhuma das normas extinguiu o ritual de passagem entre os dois âmbitos de ensino.

0 fato de a legislação não exigir formação primária ao ingresso no ginásio, ao longo do período em análise, provocou um efeito direto na seleção de documentos arquivados nos prontuários dos alunos pelas administrações escolares. Nota-se uma freqüência baixíssima de documentação referente a esse percurso.

1. Os documentos oficiais citados ao longo do texto estão disponíveis em Abreu (1935 e 1939), Bicudo (1942a, b, c, d) e Brandão (1952). 
As quatro instituições privadas, das cinco investigadas, ofereciam à época o curso primário. A instituição pública não possuía educação elementar, mas o seu certificado de admissão era válido para o ingresso em qualquer ginásio do Estado. Esse é um dos motivos que explica a alta concorrência observada no exame ali realizado, além de levar à suposição de que os candidatos inscritos para o exame deveriam se preparar preliminarmente em cursos primários ou preparatórios.

$\mathrm{Na}$ coleta das informações, houve impossibilidade de verificar o percurso escolar anterior ao ingresso no ginásio, em duas instituições da amostra - em uma das privadas e na pública. Por isso, os dados dispostos na Tabela 1 são relativos apenas às três instituições onde foi possivel fazer uma coleta consistente.

Tabela 1: Percurso escolar anterior ao exame de admissăo.

\begin{tabular}{|l|c|c|c|c|}
\hline \multicolumn{1}{|c|}{ Instituições } & A & B & E & Total \\
\hline Total de alunos matriculados & 37 & 32 & 25 & 94 \\
\hline Fizeram primário & 32 & 22 & 18 & 72 \\
\%o & 86,5 & 68,8 & 72,0 & 76,6 \\
\hline
\end{tabular}

A análise dos dados da Tabela 1 aponta o alto índice $(76,6 \%)$ de ingressantes com experiência no Ensino Primário, além disso, os registros revelam que esses alunos permaneciam, no curso secundário, na mesma instituição de ensino que haviam freqüentado no primário. Essa constatação é significativa, pois evidencia a existência de unidade e progressividade entre os dois âmbitos de ensino, nas instituições em apreço - uma articulação que na legislação de ensino não parece existir, bem como é pouco considerada na literatura especializada.

Esse fato levou à formulação do conceito de instituição progressiva com o objetivo de qualificar as barreiras institucionais existentes no que se convencionou chamar genericamente de ensino elementar. No âmbito elementar de ensino, o conceito exprime a segmentação dissimulada que, apesar de um recrutamento cada vez mais abrangente à época, não proporcionava eqüidade de oportunidades de escolarização ao desenvolver mecanismos internos que restringiam a uma pequena fração da população o avanço na escolaridade.

A análise das estatísticas produzidas oficialmente permite identificar a drástica redução de atendimento na passagem do Ensino Primário para o Secundário, bem como as taxas de seletividade que ambos produziam. No entanto, tais estatísticas se mostram pouco úteis para qualificar o padrão de seleção operado em cada âmbito de ensino, assim como entre os dois âmbitos, como se pode verificar na Tabela 2 .

Foi, sem dúvida, para uma pequena porcentagem da população da escola elementar que se abriram possibilidades de prosseguir estudando no Ensino Secundário. Nota-se, no entanto, por meio da análise dos dados constantes da Tabela 2, que o próprio curso primário apresentou um baixo índice de conclusões, tendo em vista o seu número de matrículas. Vale lembrar que, para especificar a questão da seletividade, seja no Primário, seja no Secundário, ou entre eles, é preciso considerar o fluxo escolar. Os dados acerca do fluxo no Ensino Primário fundamental comum, para o estado de São Paulo, estão na Tabela 3.

Pela análise dos dados constantes da Tabela 3, observa-se que o fluxo do ensino elementar no Estado de São Paulo foi truncado. Nos três anos analisados, nota-se que, ao mesmo tempo em que aumenta o nível de escolarização dos alunos, acentua-se significativamente a queda no número de matrículas. Além disso, na

Tabela 2: Movimentaçăo escolar, Primário e Secundảrio - cidade de São Paulo.

\begin{tabular}{|c|c|c|c|c|}
\hline Movimentasio eseolar & \multicolumn{2}{|c|}{ Ensino Primirio } & \multicolumn{2}{|c|}{ Ensino Secundário } \\
\hline & 1936 & 1937 & 1936 & 1937 \\
\hline Matricula neral & 148.735 & 156.660 & 15.605 & 17,496 \\
\hline Matricula efetina & 117.312 & 123.592 & 14.921 & 16914 \\
\hline Frequèncis & 107.390 & 114343 & 13.461 & 15.199 \\
\hline Asrovario & 86.134 & 69.288 & 12.547 & 14,000 \\
\hline Conclasbes & 16.002 & 12.024 & 1.001 & 1031 \\
\hline
\end{tabular}

Fonte: Tabela elaborada a partir do Anuário Estatistico do Brasil (1941, p. 800 e ss). 
Tabela 3: Matriculas no Ensino Primário - estado de São Paulo.

\begin{tabular}{|c|c|c|c|c|c|c|}
\hline Movimentasio escolar & 1. série & 2" serie & 3" série & 4* série & 5. série & Total \\
\hline 1835 & 319.161 & 139.559 & 84268 & 44741 & 2007 & 508.750 \\
\hline 1936 & 343.259 & 143993 & 89.527 & 50.72 & 2360 & 608.855 \\
\hline 1937 & 341.596 & 163.371 & 96.882 & 56.118 & 2160 & 659127 \\
\hline
\end{tabular}

Fonte: Tabela elaborada a partir do Anuário Estatistico do Brasil (1941, p. 798 e ss).

amostra de secundaristas, foi constatado que muitos alunos que prestavam exame de admissão no $4^{\circ}$ ano primário não eram aprovados. Eles continuavam, então, a cursar a $5^{\text {a }}$ série elementar e, ao final, voltavam a realizar o exame de admissão. Em vários prontuários do ginásio estadual, foi observada a existência de mais de uma prova de admissão por aluno. Entre as provas, havia algumas que apresentavam nota suficiente, isto é, mostram que os alunos tinham sido aprovados, mas não necessariamente classificados por conta de ausência de vagas no estabelecimento público para todos os aprovados. Mesmo assim, os alunos não desistiam, voltavam a prestar o exame na instituição, no ano seguinte, pois queriam matricular-se ali (apesar de o ginásio não ser gratuito, já que apresentava inúmeras taxas escolares).

Nas escolas particulares da amostra, verificou-se que os alunos não aprovados em exames, quando do término da $4^{\text {a }}$ série primária, permaneciam na mesma instituição de ensino e faziam a $5^{\text {a }}$ série. Geralmente conseguiam o ingresso após o ano adicional. Nota-se que a escolha, ou preferência pela instituição secundária, estava feita em ambos os casos. Em todo o levantamento de informações realizado nos arquivos das instituições, só foi possivel observar um caso de aluno matriculado em instituição particular, cujo certificado de admis- são havia sido emitido pelo ginásio estadual, ou seja, o aluno fez exame na escola pública, foi aprovado, mas por conta da falta de vaga, optou pela matrícula na escola particular.

$\mathrm{Na}$ Tabela 4, apresenta-se o fluxo do ciclo secundário, constatado nas cinco escolas pesquisadas (os números referem-se ao total de matrículas nas três coortes). É preciso considerar, todavia, que apenas com a caracterização do ginasiano foi possível conhecer o percurso escolar precedente ao ingresso no Secundário, tendo em vista que o certificado de educação primária era desnecessário ao ingresso no ginásio. Foi justamente essa caracterização que permitiu criar o conceito de escola progressiva como percurso garantido aos estudantes para articular primário e ginásio - como evidenciado pela análise, em média $76,6 \%$ dos alunos eram antigos freqüentadores da mesma instituição no primário.

Assim, mesmo quando as estatísticas oficiais mostram crescimento considerável nas taxas de escolarização primária, na cidade de São Paulo, não permitem revelar que os jovens estavam, desde o início, praticamente obrigados a uma opção específica de escolarização se pretendessem continuar os estudos - em outros termos, fazer curso primário preparatório para o ensino secundário, preferencialmente seguindo a trajetória escolar na mesma instituição de ensino.

Tabela 4: Fluxo escolar dos ingressantes no ginásio.

\begin{tabular}{|c|c|c|c|c|c|c|}
\hline \multirow{2}{*}{ Situas ào do aluno } & \multicolumn{6}{|c|}{ INSTITUICAO } \\
\hline & $A$ & 8 & $\mathrm{C}$ & 0 & $E$ & Total \\
\hline Submetidos a exame admissâo & 323 & 178 & 1.095 & 232 & 158 & 1.986 \\
\hline Aprovados em exame admissjo & 227 & 172 & 391 & 227 & 133 & 1.150 \\
\hline Matriculados na 1"sćrie" & 317 & 202 & s/d & 281 & 141 & 941 \\
\hline Matriculados na $4^{\prime}$ série = $1^{\circ}$ ciclo* & 171 & 83 & $5 / d$ & 141 & 110 & 505 \\
\hline Oriundos da turma nriginal & 69 & 37 & s/d & 52 & 57 & 215 \\
\hline Matriculados na $5^{a}$ strie - $1^{\circ}$ ciclo"*t & 35 & 21 & sid & 43 & 41 & 140 \\
\hline Oriundos ds turma original & 17 & 14 & s/d & 12 & 24 & 67 \\
\hline
\end{tabular}


Tabela 5: Percurso anterior por tempo de permanência para a conclusẵo do ginásio".

\begin{tabular}{|c|c|c|c|c|}
\hline \multicolumn{5}{|c|}{ TEMPO OE PEQOANENICLA } \\
\hline Percurso anterior & Fora do tempo & No tempo & N20 conduiram" & TOIAL"- \\
\hline Fez primbrio & 11 & 30 & 32 & 73 \\
\hline linha to & 15,1 & 41,1 & 43.8 & 100.0 \\
\hline coluni $P_{0}$ & 27,5 & 47,6 & 36.4 & 38,2 \\
\hline Sem informaç3ిo & 29 & 33 & 56 & 118 \\
\hline Finha $4 \%$ & 24,4 & 280 & 47,6 & 100,0 \\
\hline coluna क力 & 72.5 & 52,4 & 63.6 & 61,8 \\
\hline Total de Amostra & 40 & 63 & 88 & 191 \\
\hline linha to & 210 & 33.0 & 460 & 100,0 \\
\hline
\end{tabular}

* Na Peforma de 1991 , 0 ginisio tinha cinco anos de duracto $\mathrm{e}$, em 1942 passou pora quatro anco.

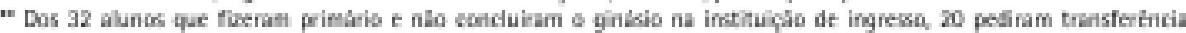

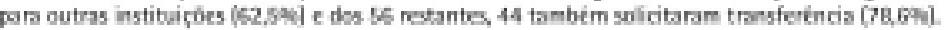

-- Nessa tabela, a total de alunos que fieram primário è 73, diversamente dos dodos constantes da Tabela 1 (72l pois

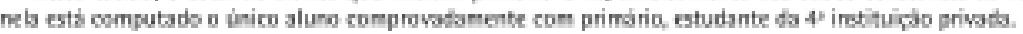

É relevante ressaltar que, desde o começo do século XX, no Brasil, modificaram-se as estratégias familiares de transmissão, manutenção e aumento de patrimônio - caracterizado, até o final do século XIX, principalmente pelo produto de atividades agrárias, posse e herança de bens materiais e matrimônio. As famílias passaram a investir e a depender cada vez mais de processos longos de escolarização. Tal mudança não se restringiu apenas a famílias provenientes da elite, mas se verificou também em outros estratos sociais que, se não investiam prontamente na educação dos filhos, passaram a ansiar crescentemente por ela, reconhecendo e reafirmando a passagem pela escola como símbolo de status e diferenciação social.

Dois instrumentos escolares auxiliaram a produzir - e, em certa medida, a reproduzir - a hierarquia de poder econômico e social, na época, na mesma medida em que ajudaram a estratificar o acesso a processos cada vez mais longos de formação, foram: os exames de admissão, que aferiam habilidades, conhecimentos e atitudes dos aspirantes, operando, no caso da cidade de São Paulo, uma seleção marcada por diferenças escolares preexistentes; e os certificados outorgados por essas instituições aos que conseguiam completar ciclos cada vez mais elevados de escolarização.

A segmentação, desde a base do sistema de ensino, configurava organização que realimentava as vantagens de freqüentadores das escolas progressivas - produzindo, ao mesmo tempo, desvantagem aos que a elas não tinham acesso -, visto que a opção inicial por esse tipo de estabelecimento acabava definindo de forma inconteste o caminho escolar futuro. Ademais, os estudantes da mesma instituição, desde o primário, foram os que proporcionalmente mais concluíram o primeiro ciclo secundário sem repetência (sem contar que apresentaram índices mais baixos de transferências entre escolas), conforme mostra a Tabela 5 .

0 sucesso em uma faixa de escolaridade mais elevada - no caso, o ginásio - esteve ligado significativamente ao percurso escolar anterior. Em suma, o alcance do percurso escolar se via definido desde muito cedo.

Estabelecer um padrão de recrutamento para o ginásio, e reforçá-lo ao longo de vários anos, teve como conseqüência a constante valorização das instituições progressivas que, na cidade de São Paulo, eram todas privadas. Tal constatação, ligada ao fato de só haver na capital um único ginásio público e uma grande diversidade de escolas elementares, conforme se verifica na Tabela 6 , que potencialmente poderiam formar candidatos para ocuparem as vagas no secundário, mas em geral não o faziam, acabou auxiliando a produzir traço de cultura de que a franquia para o prosseguimento dos estudos se conquistava nas instituições particulares - as únicas a oferecerem cursos preparatórios para os (seus próprios) ginásios².

2. No período, houve um movimento crescente das escolas primárias privadas no sentido de ampliar o atendimento a seus alunos. Elas passaram a criar cursos ginasiais e a solicitar, cada vez mais do governo federal, a inspeção preliminar, necessária à equiparação de seus cursos ao ginásio oficial (Abreu, 1935; 1939; Bicudo, 1942c). 
Tabela 6: Dependéncia Administrativa dos estabelecimentos de ensino primário - cidade de São Paulo.

\begin{tabular}{|l|c|c|c|}
\hline Ensine Primárie Geral* & 1935 & 1936 & 1937 \\
\hline Público estadual & 251 & 253 & 260 \\
\hline Público municipal & 196 & 216 & 225 \\
\hline Particular & 140 & 147 & 148 \\
\hline Total & 587 & 616 & 633 \\
\hline
\end{tabular}

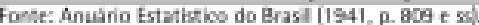

- Inchui o encino comum e o supletivo

Considerando-se ainda que, no período em tela, eram poucas as escolas secundárias reconhecidas na cidade - em 1934, eram 39 ginásios equiparados e, em 1938, 60 -, praticamente todas mantidas por particulares, e que a partir de 1931 submeteram-se às medidas intervencionistas do governo Vargas, com sua vocação centralizadora e autoritária, faz-se necessário voltar a análise para as formas de relacionamento e de regulação definidas entre a burocracia pública e os interesses privados no que toca especificamente ao exame de admissão e à definição do padrão de recrutamento que estabeleceu.

\section{Notas sobre o marco regulatório do exame de admissão}

Antes de tratar das principais regras que ordenavam o exame, faz-se necessário considerar que são expressão de relações sociais específicas, travadas em uma sociedade que se organizava em torno do modo de produção capitalista. 0 Estado é parte constitutiva dessas relações e garante a sua reprodução não apenas no que se refere ao aspecto econômico, mas também articulando e acomodando os diferentes interesses das classes sociais e proporcionando as condições necessárias para a reprodução das relações entre elas. 0 Estado, no capitalismo, organiza e controla as relações sociais, bem como a dominação nelas engendrada, ao desempenhar um papel mediador do conjunto das relações que define a classe dominante como tal, assim como reafirma a posição das classes dominadas, fazendo reproduzir as condições para a dominação de uma sobre a outra.

Essa mediação é fundamental para a garantia da própria reprodução do sistema ca- pitalista, ao limitar o interesse imediato e individual dos representantes da classe dominante - qual seja, a extensão ilimitada das condições de exploração, que se permitidas levariam à eliminação da classe dominada e do próprio sistema de produção - e ao considerar e fazer valer por meio do aparato legal, entre outros mecanismos, os interesses contrários às exigências imediatas da classe dominante. Essa função coativa assegura a realização, no longo prazo, do interesse geral da própria classe dominante (e não de um interesse geral comum a todos): a reprodução das relações de dominação (O’Donnell, 1990).

As características das instituições públicas e de sua organização burocrática no governo Vargas materializaram o processo de produção, circulação e exercício do poder, típico das sociedades em processo de industrialização. $\mathrm{Na}$ década de 1930, o poder executivo e suas instituições se organizaram crescentemente no sentido de centralizar e profissionalizar métodos de gestão e pessoal, na mesma medida em que estenderam as suas funções, passando a intervir de forma mais contundente e, ao mesmo tempo, mais impessoal nas relações sociais. Ampliaram equipes, criaram cargos e regras para preenchê-los, exigiam relatórios, despachavam avisos, enfim, davam forma a uma engrenagem que fazia descer ordens e subir informações.

A criação do Departamento de Administração do Serviço Público (DASP), em 1938, foi um marco na racionalização desse serviço. Teve como meta a institucionalização de um sistema de recrutamento por mérito, a regulamentação do acesso à carreira funcional por concursos públicos e a definição de um plano de carreira subordinado a critérios de mérito e eficiência. Essas mudanças se colocaram como ruptura e modernização frente ao modelo de gestão da Primeira República, como o avesso da tradição patrimonialista, de troca de favores e lealdade e de compromissos políticos no preenchimento dos cargos públicos nos diferentes níveis de governo.

As burocracias acabam constituindo fonte útil para organizar e conter as diferenças de classe 
na medida em que diluem a distância entre elas. A crescente divisão do trabalho e da autoridade produz modulação das hierarquias ocupacionais e de poder e, com a profissionalização, marca o sentido de modernidade e neutralidade, pelo planejamento, pela técnica e pela racionalidade das ações. A organização burocrática dissimula, assim, a origem e os objetivos do poder que lhe é subjacente.

0 burocrata faz das normas um fetiche: sua meta é fazer cumpri-las. As regras não funcionam como um meio para atingir um determinado objetivo, mas como finalidade mesma do trabalho burocrático. Para o burocrata, são as leis que expressam a virtude, e não os homens, que temiam em descumpri-las. Centraliza-se aí o próprio sentido de seu dever e de suas decisões: um sentido inscrito em regulamentos, decretos, circulares, portarias etc.

0 objetivo dessa organização, segundo Mills (1969), é fazer com que:

[...] as pessoas interiorizem o que a administração deseja que elas façam, sem que tomem consciência das motivações reais de seus atos [...]. Na passagem da autoridade para a manipulação o poder passa do visível para o invisível, do conhecido para o anônimo. (p. 129)

Como visto, a regulamentação e a fiscalização do Ensino Secundário incidiram predominantemente sobre a iniciativa privada, deixando as burocracias de ambas as esferas frente a frente, negociando e mantendo relações muitas vezes tensas. No que se refere ao ingresso no ginásio, o Departamento Nacional de Ensino (DNE) divulgou normas que dispunham minuciosamente sobre o conteúdo, a forma e todas as etapas envolvidas na realização dos exames de admissão (Portaria s/n, de 15/04/1932) - um documento fundamental que definiu as linhas gerais do exame até o final de 1940. Essas instruções foram publicadas após a promulgação da reforma de Francisco Campos e reiteraram a composição das bancas examinadoras e o seu caráter oficial: para os estabelecimentos sob regime de inspeção permanente ou preliminar, eram três professores do próprio estabelecimento, além da fiscalização do inspetor.

De um lado, a definição da composição das bancas examinadoras, com a presença de um funcionário público federal, foi uma resposta oficial no sentido de intervir e moralizar os exames de admissão, algo que estava contido nas diversas propostas em circulação, no final da década de 1920, quanto ao recrutamento dos ginasianos. Por outro, a composição das bancas examinadoras parece uma estratégia de acomodar e mostrar certa disposição para aliança entre os agentes educacionais mais diretamente envolvidos no processo - escolas e governo -, promovendo uma imagem de credibilidade recíproca. 0 governo inspecionava, regulava e certificava os exames e as escolas promoviam um ensino primário preparatório de qualidade e faziam valer as regras de recrutamento. Juntos, auxiliavam-se mutuamente no sentido de garantir uma imagem moderna, de imparcialidade aos exames e da aprovação por mérito dos alunos.

É preciso destacar que o debate sobre o local e a composição das bancas examinadoras foi travado no mesmo ambiente de outro impasse, igualmente presente no final da Primeira República, qual seja, o embate entre defensores da centralização e da descentralização do controle e das responsabilidades de administração política e pedagógica do Ensino Secundário. 0 governo Vargas encerrou essa discussão ao produzir o controle sobre esse ensino não pela oferta de vagas públicas, mas pela inspeção oficial da esfera privada, exercendo sobre as instituições de ensino particulares uma função virtualmente educativa (Vianna, 1997).

A grande quantidade de normas é expressão desse papel. Além disso, foi possível flagrar a reação das instituições frente a algumas iniciativas do governo nesse sentido em registros feitos pelos inspetores e em livros de visita encontrados nos arquivos das escolas pesquisadas. Por isso, a descrição das principais prescrições legais referentes à admissão ao ginásio se fará permear pelos relatos dos inspetores em diver- 
sas situações exemplares, reveladoras das tensões delas derivadas.

Não era nova a tendência, nos debates sobre a educação nacional, que pugnava por uma orientação superior para o ensino, que visasse à concordância entre leis e meio, procurando identificar as "verdadeiras necessidades sociais" derivadas do espírito de modernização e defendendo a continuidade legal com um vasto plano para a educação. Isso estava presente em algumas reformas estaduais, conduzidas na década de 1920. Nesse sentido, a Educação era entendida como uma questão de caráter universal, com força para apaziguar divergências.

Assim, as normas instituídas pela burocracia do Ministro Francisco Campos foram compreendidas, por muitos, como respostas ao movimento renovador da Educação, presente nos últimos anos da República, que era uma tentativa de revestir o Ensino Secundário de um caráter moderno. 0 caminho instituído por aquela gestão tinha como fundamento os ideais de harmonia e cooperação entre os diferentes estratos sociais em prol da construção de uma "nação nova". A intervenção do Estado era tida como uma estratégia eficaz para promover a necessária mudança social em direção à modernidade, ao mesmo tempo em que deveria visar ao consenso para obter unidade orgânica entre Estado e sociedade.

Esses traços são típicos da modalidade de corporativismo implantado por Vargas, que criou inúmeros órgãos técnicos, conselhos e comissões, no interior da burocracia estatal, e em muitos deles abriu espaço para a representação de interesses privados. 0 Conselho Nacional de Educação, por exemplo, tinha um caráter consultivo e funcionava como fórum de debates entre "técnicos, educadores e representantes de instituições" e como arena de negociação entre os setores público e privado de ensino (Miceli, 2001).

Não foi fácil ao governo conciliar politicamente e obter o apoio das diferentes demandas vindas de projetos educacionais em circulação no período - tais como os da lgreja, das Forças Armadas, da ABE. 0 próprio objetivo de produzir consenso propiciou à iniciativa privada uma mar- gem de manobra e o exercício de uma pressão considerável sobre as decisões relativas aos exames de admissão - para não dizer sobre a toda a política educacional voltada ao Ensino Secundário.

Uma das evidências, nesse sentido, foi a realização descentralizada do exame - conduzido isoladamente em cada estabelecimento de Ensino Secundário e elaborado pelo respectivo corpo docente -, permitindo certa independência para cada instituição, que podia constituir uma "identidade" para o exame de acordo com seus interesses e possibilidades.

A análise das demais orientações, contidas também na Portaria de 15/04/1932, leva a apontar o mesmo sentido geral: o governo como agente legal para a vigilância de instituições privadas de ensino.

As instruções exigiam publicidade para o exame, sendo preciso afixar, na porta dos estabelecimentos, os editais sobre o prazo e os documentos para a inscrição; impunham obrigatoriedade na divulgação das chamadas das provas escritas e orais, que também deveriam ser afixadas na porta do estabelecimento e, quando possível, publicadas em jornais matutinos de maior circulação, controlando o número de alunos de cada turma para as provas escritas, de acordo com a capacidade das salas e com as exigências de fiscalização, a juízo do inspetor.

Sobre problemas com a divulgação dos resultados de exames, segue o relato de um inspetor:

Continuamos a identificar as provas de admissão e apurar as médias de acordo com a lei. Lembro ao Reitor do Colégio, que não é permitido publicar, quer dentro do Colégio, quer ainda, em impressos, como foi feito, as médias finais de admissão sem prévio visto do Inspetor Federal (quanto ao curso secundário) e que para evitar males futuros, os trabalhos de apuração de médias e identificação de provas não deve estar sujeito a correrias muitas (12/12/1937).

A publicidade indesejada das médias finais de exames, à qual o inspetor fez referência, esta- 
va contida em publicação institucional do colégio, distribuída no início do ano aos interessados, com o objetivo de divulgar o calendário do ano letivo, homenagens a pessoas importantes para a comunidade, premiações e condecorações de alunos, entre outras. Nota-se a pressão e o atropelo da instituição de ensino em relação à cronologia das ações do agente público, tendo em vista as vantagens e o senso de oportunidade que se colocavam para o colégio. Mesmo quando convergem os interesses de ambas as esferas, as relações muitas vezes não eram tranqüilas.

Os inspetores deveriam fiscalizar todo o processo de exame, cabendo-lhes a retirada de candidatos que, por qualquer motivo, cometessem infrações aos preceitos legais. Poderiam suspender os julgamentos que lhes parecessem irregulares, submetendo o seu ato à apreciação do inspetor regional que, se julgasse conveniente, notificaria à Superintendência. Sobre esse aspecto, há o seguinte relato de inspetor:

Iniciamos dentro da ordem legal as provas de admissão ao $1^{\circ}$ ano, tudo ocorreu normalmente e estiveram presentes 62 examinandos. Anulei a prova de Geografia do aluno JA4 por ter fraudulentamente trocado o número do ponto sorteado; o mesmo realizou provas em $2^{\text {a }}$ chamada hoje de Geografia e Literatura ( 5 a série primária). Em tempo: determino ao diretor que sejam aplicados todos os artigos de lei referentes às provas de admissão oral, assim como os processos das mesmas $(01 / 12 / 1937)$.

Além disso, as instruções informavam que o resultado do exame se faria lavrar em livro próprio, assinado pela comissão examinadora e pelo inspetor. Terminados os exames, os candidatos seriam classificados segundo os pontos obtidos e os resultados deveriam ser divulgados. Sobre a publicidade da ordem de classificação, a inspetora de uma das escolas afirma:

Foi hoje afixado na portaria deste estabelecimento o termo de classificação dos exa- mes de admissão. Acha-se quase terminado o meu relatório de Novembro, no qual estive hoje trabalhando $(04 / 02 / 1935)$.

Como determinado pelo Decreto $\mathrm{n}^{\circ} 19.890$ - e especificado pela Portaria de 15/04/1932 -, os inspetores deveriam enviar mensalmente à Divisão do Ensino Secundário (DES) relatórios sobre suas atividades de fiscalização. É importante ressaltar, entretanto, que a maior parte dessa documentação não era elaborada pelo servidor público, mas por funcionários das secretarias das escolas. 0 inspetor apenas conferia as informações e assinava os relatórios.

Se, de um lado, esse fato permite compreender uma das faces do "sucesso" da fiscalização e regulamentação do ensino secundário - fruto do desenvolvimento e da ação da burocracia privada, que viria a se consolidar como espelho para a organização e o funcionamento dos ginásios públicos, nas décadas seguintes, com prejuízos enormes para a vida escolar dos estudantes -, de outro, mostra que o envolvimento de vários agentes no "sobe e desce de ordens e informações" abre a possibilidade de ações não exatamente planejadas, técnicas ou racionais, como hipoteticamente deveria se configurar o funcionamento das burocracias pública e privada - isto é, não garante a "neutralidade", no caso da elaboração dos relatórios, na medida em que os seus realizadores estavam freqüentemente sob o comando da direção dos colégios, incentivados a fraudar resultados quando "necessário", podendo alegar, posteriormente, equívoco involuntário.

Mesmo sob rigorosa inspeção, as instituições de ensino não mediam esforços para defender seus interesses e de seus clientes e, freqüentemente, contavam com a "simpatia" e a confiança dos inspetores que eram, muitas vezes, ex-alunos das escolas ou mesmo ex-professores. Contavam, assim, com o fato de que as propostas de modernização vindas da esfe-

3. Os nomes de alunos e instituições partícipes da amostra foram abreviados, como forma de preservar a identidade, respeitando acordo travado. 
ra pública deixavam-se permear por persistências da tradição patrimonialista como a troca de favor e a lealdade.

Em relato de inspetor acerca de irregularidades detectadas na vida escolar de um aluno, ficou evidente a "proximidade nociva" na relação entre as burocracias:

De acordo com o meu digno antecessor na Inspeção que, em virtude da confiança na direção da casa, havia assinado os certificados anteriores, resolvemos anular todo o curso do aluno e documentos por nós assinados.

Esse primeiro mecanismo regulador do acesso ao Ensino Secundário (Portaria de 15/04/ 1932), bem como os posteriores, portavam valores como os de ordem, disciplina, hierarquia, cooperação, subordinação. Apesar das resistências, esses valores foram paulatinamente se inscrevendo na própria lógica de funcionamento das instituições e acabaram desempenhando o papel de reproduzir de forma ampliada e impessoal os mecanismos seletivos de inclusão individual na já estratificada organização das escolas.

Todas as medidas buscavam controlar e conferir seriedade, publicidade e legitimidade ao processo de exames. Além disso, ao exigir de alunos, instituições e representantes da burocracia oficial o desempenho de funções específicas e o estreito cumprimento de etapas, o ritual dos exames acabava produzindo uma identidade ao processo, fomentando alianças entre todas as partes envolvidas e definindo um padrão de distinção que agregava valor ao ingresso no ginásio no mercado das disputas por mobilidade social em momento de crescente divisão de funções.

Ainda em 18 de novembro de 1932, novas instruções para o exame foram expedidas, revelando a disposição do governo em aumentar o rigor burocrático sobre o processo. As novidades diziam respeito à apresentação de recibo de pagamento de taxa e de requerimento de inscrição - a serem apresentados na secretaria do estabelecimento de ensino no máximo em até três dias antes do início das provas, tendo o último que ser firmado sob estampilha federal de $2 \$ 000$ (dois mil réis); a inscrição deveria ser submetida ao visto do inspetor; e o certificado de aprovação do exame deveria estar de acordo com o modelo oficial, sendo assinado pelo inspetor e com estampilha federal de $1 \$ 000$ (mil réis) - documentos fartamente encontrados nos prontuários dos alunos.

0 certificado do exame, cujo valor era reconhecido e garantido oficialmente por estampilhas e rubricas de funcionários públicos, tornava-se um passaporte para novos caminhos, permitindo ao sujeito galgar posições de respeito e reconhecimento social. Para os aspirantes ao ginásio, tratava-se de luta pessoal-assimilada isto é, uma luta incitada pelo contato com modelos de projeto de vida, em circulação no mercado hierarquizado de possibilidades de inserção social, e pelo contato com outras instituições sociais com as quais conviviam, desde a família até os meios de comunicação de massa.

Relembrar, reiterar, reproduzir incansavelmente as normas, além de produzir novas, foram características constantes no período. É um comportamento que deixa entrever o tipo de relação estabelecida entre governo federal, inspetores e estabelecimentos de ensino: além de cumprir um papel educativo, revelam a existência de transgressão nas instituições fiscalizadas.

Com Gustavo Capanema no comando do Ministério da Educação e Saúde Pública e já sob o regime do Estado Novo, as regras de realização do exame sofreram novas alterações. Em 16/02/ 1938, o Ministro instituiu a Portaria $\mathrm{n}^{\circ} 13$, que trata do regime didático e escolar dos estabelecimentos. Essa Portaria modificou o cálculo da média final e determinou que as provas escritas fossem eliminatórias, além de instituir novas instruções. 0 fruto de tal medida se manifestou já, em 25/02/1938, em relato de um dos inspetores:

Realizaram-se nesta data as provas escritas de Matemática do presente exame de admissão. Foram inabilitados 28 dos 43 alunos inscritos, impossibilitados, portanto, de prosseguirem os exames. 
Capanema reafirmava a $1^{\text {a }}$ época de exames, realizada em dezembro, como exclusiva para os alunos que estavam matriculados no primário das instituições em que prestavam os exames. Além disso, atribuía-lhe um caráter de concessão especial, com distribuição específica das taxas arrecadadas: 20\% dos recursos iam para o patrimônio do estabelecimento, 70\% iam para a banca e $10 \%$ ficavam com inspetor - que em $2^{a}$ época de exames não ganhava tal porcentagem por ser considerada época regular.

A distinção entre as épocas, presente nas normas, promovia como conseqüência crescente valorização das instituições progressivas, reforçando a cultura de que a qualidade educacional residia naquele tipo de escola, todas privadas.

0 controle do governo central sobre as instituições se intensificou. Em 30 de novembro de 1938, Abgar Renault, o então diretor geral do DNE, baixou a Portaria $n^{\circ} 624$ com novas instruções para os estabelecimentos sob inspeção federal. Informava a necessidade de se considerarem nulas, sob todos os efeitos, as matrículas e conseqüentes atos escolares de alunos que, em exame de admissão à $1^{\text {a }}$ série, não tivessem obtido a média igual ou superior a 50 - exigência contida em instruções anexas à Portaria de 15/04/1932.

Mais uma vez, o fato de o diretor do DNE mostrar a necessidade de reiterar um regulamento anteriormente fixado evidencia a existência de burla às normas, uma resistência proveniente tanto de estabelecimentos quanto de inspetores. Isso se evidenciou no relato, de $02 /$ 04/1939, em que o inspetor mencionou o termo de anulação de curso de um aluno, que havia sido transferido em fevereiro daquele ano para outro colégio:

Em virtude de um exame acurado nos documentos dos alunos iniciado em princípios de Março, encontrei uma grave irregularidade nos documentos do aluno SL, que, em virtude de não ter sido aprovado no exame de admissão em Dezembro de 1934, conseguiu burlar toda a Inspeção, até a minha, e cursou a partir de 1935 a primeira e as demais séries deste Colégio. Conseguindo ainda guia de transferência assinada por mim, em confiança da idoneidade do Colégio e seus funcionários, sem exame de documentos anteriores. De acordo com o meu digno antecessor na Inspeção que em virtude da confiança na direção da casa, havia assinado os certificados anteriores, resolvemos anular todo o curso do referido aluno e documentos por nós assinados, e lançamos nosso sentido protesto por tamanha falta que incorremos, vitimas de boa fé. A resolução seguiu hoje por telégrafo à devida Repartição de Ensino e foi por mim comunicada ao Sr. Inspetor do Colégio SL.

Em função, provavelmente, das pressões dos estabelecimentos de ensino e dos familiares dos alunos, bem como por uma quantidade significativa de transgressões, o diretor geral do DNE abriu, na própria Portaria, a possibilidade de legalizar a condição desses alunos com uma nova habilitação em exame de admissão e, após este, em exames especiais, à matrícula no ano letivo de 1939, na série em que os alunos estariam normalmente inscritos. Os exames e as provas especiais deveriam ser requeridos em janeiro para serem realizados em fevereiro de 1939 no estabelecimento em que o aluno tivesse cursado o ano letivo de 1938. Algo que também se verificou em estabelecimentos da amostra, como evidencia o seguinte relato:

Lanço este termo de visita para cancelar a matrícula do aluno PFW, por ter feito exame de admissão em 2 e 3 de Dezembro de 1937 sem idade necessária, pois nasceu em 27 de junho de 1928. 0 aluno querendo poderá requerer exame de admissão este ano.

Dias depois, o inspetor envia uma carta ao diretor da DES, dizendo o que segue:

Dei fiel cumprimento às ordens emanadas do parecer, resolvendo porém, não matricular o aluno PFW, como era ordenado, por 
ter o referido aluno se sujeitado a um novo exame de admissão este ano, no qual foi reprovado. De acordo com a Lei, válido é o último exame prestado, razão pela qual, tomo esta atitude, da qual peço a V. Excia. um melhor juízo e aprovação.

Em abril de 1942, instituída a Lei Orgânica do Ensino Secundário, o curso sofre reestruturação. Para o ingresso no ginásio, a lei continua a determinar idade mínima de 11 anos e exigir exame de admissão, mas passa a permitir aos alunos repetir o exame em $2^{\text {a }}$ época caso não obtivessem aprovação em primeira.

Ainda no final do ano, a DES advertiu os inspetores que aqueles que permitissem a realização, mesmo que condicional, de exames de admissão a candidatos que não respeitassem o limite de idade fixado na lei, seriam passíveis de dispensa. Em relação ao rigor na comprovação da idade para a realização de exames, os registros dos inspetores deixam entrever, à análise, a dificuldade que enfrentavam, tendo em vista as diversas pressões dos estabelecimentos de ensino, bem como dos pais dos examinandos. Há um exemplo típico dessa situação nos seguintes relatos de um inspetor:

Declaro encerrado o tempo de inscrição para os exames de admissão, de acordo com o artigo $20, \S 1^{\circ}$, do decreto 21.241. Recusei o requerimento dos alunos: EDNJ, AD, JSFA e OFN, todos por falta de idade legal... Em tempo - ao terminar este termo de visitas, chegou a certidão de nascimento do examinando OFN, tendo como data de nascimento $10 / 08 / 1925$ e não de 1926 , conforme havia estado escrito no seu requerimento.

Dias depois, o inspetor prossegue:

Visitei hoje o ginásio, dei andamento a diversos papéis referentes aos exames de admissão. Devido a insistentes pedidos do $\mathrm{Sr}$ Secretário e dos pais dos alunos que não têm idade legal para prestar exames de ad- missão, resolvi admiti-los condicionalmente. Estes examinandos são três, conforme consta do termo de visita do dia 16: EDNJ, $A D$ e JSFA. Devo fazer notar que o examinando BMO desistiu de prestar exame neste ginásio, ficando assim reduzido a 32 alunos os que estão em condições legais, e três admitidos sob condição de recorrerem à Inspetoria Geral para validade dos exames por serem menores da idade legal.

Apesar de intensa, a interferência operada pela burocracia pública, no que toca ao acesso ao secundário, cumpriu restritamente as funções de regular e fiscalizar esse âmbito de ensino e, muitas vezes, nem mesmo teve êxito completo. 0 governo não participou diretamente da oferta ou ampliação do número de vagas e, com esse tipo de atuação, não lhe foi possível articular ativamente as estratégias de escolarização secundária, sendo quase que completamente dependente do sistema privado de ensino. Exemplo disso foi a indiferença quanto à reforma de Capanema, no que toca ao controle das anuidades dos estabelecimentos particulares de ensino e à reserva de uma porcentagem de vagas gratuitas, com o objetivo de disseminar o Ensino Secundário a um público de menor poder aquisitivo. De acordo com Schwartzman et al. (2000), "a lei da reforma, no que se refere ao controle dos lucros das escolas privadas, permaneceu letra morta” (p. 218).

Frente às estratégias muitas vezes bem sucedidas das instituições privadas de ensino para contornar as normas, quando lhes despertava interesse, o papel do Estado como repressor dos interesses individuais e imediatos da esfera privada e a função coativa da burocracia pública promoviam, paradoxalmente, efeitos atrofiados e frágeis. Em alguns momentos, os relatos dos inspetores mostram a debilidade de seu arbítrio e o poder das instituições privadas frente a decisões cotidianas como mostram os seguintes relatos:

Em virtude de ser necessária uma certa liberdade da Divisão do Ensino Secundário, 
digo melhor, em virtude de dar plena e ampla liberdade à DES, resolvi insistir na minha transferência deste Colégio, para outro, para a mesma decidir sobre as comunicações feitas por esta inspetoria, referentes às irregularidades que encontrei no arquivo e na vida escolar dos alunos, bem assim como outras insolvências das leis. Para evitar qualquer dúvida futura, passo a copiar o documento autenticado pela Exima DES, onde se lê o meu pedido de transferência: "Senhor Diretor, havendo assumido perante V. Excia a responsabilidade de apontar graves irregularidades no arquivo do Estabelecimento em que exerço minhas atribuições de inspetor, venho solicitar-lhe, como manda a ética, minha transferência, a fim de que possa a comissão designada para apurar as ditas irregularidades, quando aqui chegar, ter a mais ampla liberdade em sua ação. Respeitosas saudações”.

Alguns dias depois, o inspetor reproduz o telegrama que concede a sua transferência e afirma:

Em virtude do exposto, a partir do dia 15, não serei mais o inspetor deste estabelecimento. Desde já lavro minha despedida, comparecendo dia 16 (talvez) para dar posse ao meu digníssimo sucessor. Ao sair desta casa, retiro-me com a consciência tranqüila por ter cumprido o meu ofício com todo o escrúpulo e sinceridade, simplesmente magoado por ter tido muita confiança no bom nome do estabelecimento, razão pela qual fui obrigado mais tarde, em virtude de dúvidas a esta confiança e idoneidade do colégio (quanto à documentações), a apontar diversas irregularidades a Exima D.D.E.S. Certamente à Diretoria não poderei deixar meus agradecimentos, porque, infelizmente o 'Inspetor', digo, o representante do Governo nesta casa, não foi tratado na altura de seu ofício; porém, como Sacerdote e representante de Deus, deixo meu perdão e votos de tudo melhorar para a maior fama do Colégio e moralização do Ensino. Aos senhores auxiliares e professores amigos deixo o meu 'muito obrigado', pelas atenções. Hoje mesmo despedi-me dos alunos.

E por fim, um último relato acerca das tensas relações entre as burocracias, que mostra a autonomia das instituições de ensino em relação às normas e à fiscalização:

Ontem, à tarde, foi-me comunicado um telegrama do Exmo Diretor do Colégio, anunciando-me uma passeata do Colégio à cidade de Sorocaba, devendo fazer parte todo o corpo docente e discente. Considerando: a) que tais feriados estão contra as determinações da circular 625, item XXI; b) considerando que a resolução foi tomada pela Exima Diretoria e comunicada a mim só depois de tudo pronto, sem prévia combinação; c) considerando que estando bem próximas as férias de Junho e que equivaleria a começar as férias antes das determinações legais e recomendações telegráficas ultimamente recebidas do Exmo Sr. Diretor da Divisão de Ensino Secundário; ontem à tarde mesmo, por intermédio do Sr. Secretário mandei comunicar à Diretoria do Colégio que não autorizava essa passeata pelos motivos acima. Apesar da falta de autorização da inspetoria do Colégio, hoje foi realizada a passeata não encontrando o Colégio em funcionamento estando ausentes o corpo docente e discente. Determino que o Sr. Secretário afixe em lugar visível a todos o aviso impresso referente ao início e fim das férias de Junho, que deixo junto a este livro de termos.

A partir dos registros dos inspetores, é possivel entrever as tensões que marcam as relações entre os setores público e privado, além dos limites do papel repressivo e interventor do Estado na esfera educacional durante esse período histórico. 


\section{Referências bibliográficas}

ABREU, A. (Org.). Leis do Ensino Secundário e seus comentários (1931 a 1395). Imprensa Oficial, 1935.

Leis do Ensino Secundário. 2. ed. Revista e atualizada. Belo Horizonte: Queiroz Breyner, 1939.

BICUDO, J. C. (Org.). 0 ensino secundário no Brasil e sua atual legislação (de 1931 a 1941 inclusive). São Paulo: AlFES, $1942 a$.

0 ensino secundário no Brasil e sua atual legislação (de janeiro a maio de 1942). São Paulo: AlFES, 1942b.

0 ensino secundário no Brasil e sua atual legislação (de setembro de 1942 a julho de 1943). São Paulo: AlFES, $1942 c$.

0 ensino secundário no Brasil e sua atual legislação ( $2^{\circ}$ semestre de 1943 e decretos anteriores a 1931). São Paulo: AIFES, 1942d.

BRASIL. Anuário Estatístico do Brasil. Ano V, 1939/1940. Rio de Janeiro: IBGE, 1941.

MICELI, S. Intelectuais à brasileira. São Paulo: Cia das Letras, 2001.

MILLS, C. W. A nova classe média (white collar). Tradução de V. Borda. Rio de Janeiro: Zahar, 1969.

0’DONNELL, G. Análise do autoritarismo burocrático. Tradução de C. Schilling. Rio de Janeiro: Paz e Terra, 1990.

RINGER, F. Education and society in modern Europe. Indiana: Indiana University Press, 1979.

SCHWARTZMAN, S.; BOMENY, H.; COSTA V. Tempos de Capanema. São Paulo: Paz e Terra, 2000.

VIANNA, L. W. A revolução passiva: iberismo e americanismo no Brasil. Rio de Janeiro: Revan, 2004.

Recebi em 05.05.08

Aprovado em 23.10.08

Maria Angélica Pedra Minhoto, professora do curso de Licenciatura, na FEUSP, ministrando a disciplina "Política e Organização da Educação Básica no Brasil" (POEB), integrante da linha de pesquisa "Organizações e Políticas Educacionais" (CNPq), contribui para o desenvolvimento do projeto "Psicologia e estrutura do ensino secundário brasileiro". 